\title{
Caracterização do processo de rigor mortis nos músculos Gastrocnemius e Pectoralis de perus (Meleagris gallopavo) e maciez da carne
}

\section{Characterization of rigor mortis process of muscles Gastrocnemius and Pectoralis of turkey (Meleagris gallopavo) and meat tenderness}

\author{
Fábio da Costa, ${ }^{*}$ Teófilo José Pimentel da Silva, ${ }^{* *}$ Mônica Queiroz de Freitas, ${ }^{* *}$ Rogério Tortelly, ${ }^{* \star *}$ \\ Guilherme Jogaib Jardim****
}

\begin{abstract}
Resumo
Este trabalho objetivou caracterizar o processo de rigor mortis dos músculos Gastrocnemius e Pectoralis de seis carcaças de perus durante o resfriamento industrial e a maciez da carne. Foram escolhidos ao acaso seis perus machos da marca $B U \mathrm{~T}$ A (British United Turkeys of América), abatidos em matadouro sob Inspeção Federal em Carambeí, PR. Após a sangria, analisou-se a temperatura, $\mathrm{pH}$, comprimento de sarcômero em diferentes intervalos de tempo $(0,25 \mathrm{~h} ; 1,5 \mathrm{~h} ; 2,5 \mathrm{~h} ; 6 \mathrm{~h}$ e $18,5 \mathrm{~h})$ e força de cisalhamento ou maciez dos músculos. Para a comparação dos valores obtidos utilizou-se a análise da variância (delineamento inteiramente ao acaso e fatorial); o teste de Tukey ao nível de $5 \%$ e a tendência de correlação linear de Pearson. A temperatura da câmara fria variou de $32,3^{\circ} \mathrm{C}(0,25 \mathrm{~h})$ a $-0,5^{\circ} \mathrm{C}(18,5 \mathrm{~h})$ e a temperatura média das carcaças foi de $40,83^{\circ} \mathrm{C}$ e $2,40^{\circ} \mathrm{C}$, respectivamente. $\mathrm{O} \mathrm{pH}$ médio inicial do músculo Gastrocnemius foi de $6,39(0,25 \mathrm{~h})$ e o final 5,91 (18,5h) e no Pectoralis foi 6,15 e 5,59. A contração máxima do sarcômero dos músculos Gastrocnemius e Pectoralis ocorreu na 0,25 h ou 15 min. (1,59 $\mathrm{m}$ e 1,61 m) após a sangria. Os dois músculos estudados podem ser considerados como macios pois apresentam uma força de cisalhamento próximo de $6,0 \mathrm{~kg}$, demonstrando uma resolução normal do processo de rigor mortis.
\end{abstract}

Palavras-chave: carcaça de peru, músculos, rigor mortis, maciez.

\begin{abstract}
This work was designed to characterize the rigor mortis process of Gastrocnemius and Pectoralis muscles of 06 turkey carcasses during the industrial chilling and meat tenderness. Six male turkeys B U T A (British United Turkeys of América) were randomly assembled, slaughtered at Federal Inspection Slaughterhouse - Carambeí, PR. After exsanguination, were measured temperature, $\mathrm{pH}$, sarcomere length and shear force or tenderness at differents times $(0.25 \mathrm{~h} ; 1.5 \mathrm{~h} ; 2.5 \mathrm{~h} ; 6.0 \mathrm{~h}$ and $18.5 \mathrm{~h})$. To compare the values were utilized the ANOVA; the test of Tukey with $5 \%$ and tendency of Pearson linear correlation. The chilling room temperature varied between $32.3^{\circ} \mathrm{C}(0.25 \mathrm{~h})$ to $-0.5^{\circ} \mathrm{C}(18.5 \mathrm{~h})$, and the mean temperature of carcasses were $40.83^{\circ} \mathrm{C}$ and $2.40^{\circ} \mathrm{C}$, respectively. The mean $\mathrm{pH}$ of Gastrocnemius muscle was initial $6.39(0.25 \mathrm{~h})$ and final 5.91 (18.5h), in the Pectoralis muscle was initial $6.15(0.25 \mathrm{~h})$ and final $5.59(18.5 \mathrm{~h})$. The maximum contraction of sarcomere of Gastrocnemius and Pectoralis occurred at $0.25 \mathrm{~h}-15 \mathrm{~min}$. (1.59 $\mathrm{m}$ and $1.61 \mathrm{~m}$ ) after exsanguination. The two muscles studied can be considered tender, once resulted the shear force close to $6.0 \mathrm{~kg}$, showing a normal resolution of rigor mortis process.
\end{abstract}

Keywords: carcass of turkey, muscle, rigor mortis, tenderness.

\section{Introdução}

O Brasil ocupa hoje posição de destaque entre os maiores produtores mundiais de produtos de origem animal. Dentre estes, a carne e os produtos industrializados de peru, atualmente disponíveis nos supermercados, estão conquistando cada vez mais os consumidores, por tratar-se de um alimento com baixo teor de gordura e colesterol e alto teor protéico. Igualmente, é cada vez maior o número de restaurantes que oferecem em seus cardápios pratos preparados a partir da carne desta ave (Owens e Sams, 1997; Antunes, 2003).

A queda do $\mathrm{pH}$ e da temperatura durante o desenvolvimento do processo de rigor mortis das carcaças dos animais de açougue influenciam diretamente a qualidade da carne. A

\footnotetext{
* Programa de Pós-Graduação em Medicina Veterinária (Doutorado) - Higiene Veterinária e Processamento Tecnológico de Produtos de Origem Animal, Faculdade de Veterinária, Universidade Federal Fluminense - UFF.

** Departamento de Tecnologia dos Alimentos da Faculdade de Veterinária - UFF.

*** Departamento de Patologia da Faculdade de Veterinária, Universidade Federal Fluminense.

**** Discente Iniciação Científica - Faculdade de Veterinária - UFF.

Autor para correspondência: Teófilo José Pimentel da Silva. E-mail: mtatjps@vm.uff.br .
} 
velocidade do rigor mortis é controlada, principalmente, pela reserva de glicogênio, $\mathrm{pH}$ e temperatura do músculo (Ma e Addis, 1973; Lesiak et al., 1996; Molette et al., 2003). A determinação do tamanho de sarcômero demonstra uma correlação positiva entre sua dimensão e o desenvolvimento do processo de rigor mortis, bem como da maciez da carne (Ma e Addis, 1973; Mckee e Sams, 1998; Alvarado e Sams, 2000a). Por outro lado, a idade do animal é responsável em grande parte pela variação da maciez. Em animais mais velhos ocorre uma diminuição da solubilidade da proteína colágeno, resultando assim em carnes mais duras (Shimokomaki et al., 1972). A análise instrumental (força de cisalhamento) é a metodologia mais utilizada no controle da maciez das carnes (Lyon e Lyon, 1997; Mckee e Sams, 1998; Alvarado e Sams, 2000a).

O processo de rigor mortis e a maciez da carne de perus são bem similares aos observados na carne de frango, uma vez que apresentam valores de $\mathrm{pH}$ final post mortem bem próximos (Khan, 1971; Alvarado e Sams, 2000a). As características do processo de rigor mortis de carcaça de perus durante o processamento industrial para obtenção de carcaças resfriadas só foram observadas em outros países (Landes et al., 1971; Bernard et al., 1988; Owens e Sams, 1997), ainda não foram estabelecidas para as condições brasileiras.

Assim, este trabalho foi realizado com os objetivos de caracterizar o comportamento do processo de rigor mortis do peito e coxa em carcaças frigorificadas de perus; determinar o valor de $\mathrm{pH}$ e do comprimento de sarcômero da coxa e peito e suas mudanças durante a retirada do calor sensível das carcaças na câmara de resfriamento, logo após a sangria e controlar a maciez das carnes por meio da análise instrumental (força de cisalhamento).

\section{Material e métodos}

Foram escolhidos ao acaso seis perus machos, da linhagem British United Turkeys of America, com 124 dias de vida e peso vivo médio de $16,1 \mathrm{~kg}$. Os perus foram abatidos em matadouro sob Inspeção Federal em Carambeí, PR após os cuidados ante mortem que neste caso incluía o período de repouso, jejum e dieta hídrica de 12 horas antes do abate. Para o abate, os animais foram dependurados em nória mecanizada, insensibilizados, sangrados, estimulados eletricamente, eviscerados e as carcaças foram destinadas à câmara de resfriamento $\left(2,3^{\circ} \mathrm{C}\right.$ - temperatura média do ar), conforme a portaria 210 (Brasil, 1998). As carcaças foram conduzidas devidamente identificadas para a câmara frigorífica, na qual foi realizada a tomada de temperatura das carcaças com um termômetro e determinação do $\mathrm{pH}$ com potenciômetro Handylab 1- Schott, utilizando uma solução homogeneizada com $10 \mathrm{~g}$ da amostra em $100 \mathrm{~mL}$ de água destilada, nos intervalos de tempo de $0,25 \mathrm{~h} ; 1,5 \mathrm{~h} ; 2,5 \mathrm{~h} ; 6,0 \mathrm{~h}$ e 18,5 h após a sangria.

De cada carcaça foram colhidas duas amostras, nos mesmos intervalos supracitados, da coxa e do peito para determinação do comprimento de sarcômero. Com auxílio de pinça e bisturi foram retiradas amostras de aproximadamente $2,5 \mathrm{~cm}$ de comprimento por $1,5 \mathrm{~cm}$ de largura e $0,5 \mathrm{~cm}$ de espessura, previamente fixadas por garras metálicas. As garras tinham 0 objetivo de manter o músculo em condições em que se encontrava na carcaça, evitando contração ou distensão das fibras após sua retirada. As amostras foram colhidas e identificadas com o número da carcaça, hora da colheita e nome do corte para a confecção de lâminas histológicas. Em seguida foram colocadas em frascos plásticos de boca larga contendo formalina tamponada 10\% (250 mL). Após a fixação as amostras foram clivadas, desidratadas, clarificadas, incluídas em parafina e seccionadas em um micrômetro (Pika - Seiko) com espessura de 5 micra. Os cortes histológicos foram corados com Hematoxilina Eosina segundo a técnica recomendada por Behmer et al. (1976).

As lâminas foram lidas utilizando a microscopia óptica (Microcópio Nikon com luz visível em objetiva de imersão) segundo a técnica recomendada por Sloss e Kemp (1978). Este método é baseado na contagem de 10 sarcômeros de dez miofibrilas diferentes, com a mensuração do sarcômero sendo feita por uma ocular milimetrada com uma escala de 10 micrômetros. A média obtida foi multiplicada pelo fator de correção da objetiva de imersão (fator encontrado de $0,8 \mu$ ) e o valor expresso em micrômetros $(\mu)$.

Para a análise de força de cisalhamento utilizou-se a técnica descrita por Kerth et al. (1995), onde foram colhidas amostras de aproximadamente $250 \mathrm{~g}$ da coxa e do peito nos intervalos supracitados. Essas amostras foram devidamente identificadas, embaladas e cozidas até a temperatura interna de $70^{\circ} \mathrm{C}$, resfriadas e acondicionadas em caixa de isopor, sendo transportadas até o Laboratório de Tecnologia de Carnes da Faculdade de Veterinária da Universidade Federal Fluminense. Nesse Laboratório, posteriormente foram retirados sete cilindros de cada amostra de $1,27 \mathrm{~cm}$ de diâmetro e cisalhados ao meio na máquina "Warner-Bratzler Meat Shear Force - modelo 3000".

Para a comparação dos valores obtidos utilizou-se a análise de variância (delineamento inteiramente casualizado e fatorial); o teste de Tukey ao nível de $5 \%$ de significância e a tendência de correlação linear de Pearson, empregando o programa SAS Institute (SAS, 1985).

\section{Resultados e discussão}

No presente trabalho, os valores de temperatura da câmara fria foram de $32,3^{\circ} \mathrm{C}(0,25 \mathrm{~h}), 2,3^{\circ} \mathrm{C}(1,5 \mathrm{~h}), 0,4^{\circ} \mathrm{C}(2,5 \mathrm{~h}),-0,3^{\circ} \mathrm{C}$ $(6,0 \mathrm{~h})$ e $-0,5^{\circ} \mathrm{C}(18,5 \mathrm{~h})$. A análise estatística revelou diferença significativa $(p<0,05)$ entre os valores médios das temperaturas das carcaças, ocorrendo um declínio linear de $40,83^{\circ} \mathrm{C}$ até atingir $2,40^{\circ} \mathrm{C}$ no período de $18,5 \mathrm{~h}$ após o abate. Os valores médios encontrados na determinação de $\mathrm{pH}$ dos músculos Gastrocnemius e Pectoralis foram de 6,39 \pm 0,19 e $6,15 \pm 0,08$ com 0,25 horas, $6,20 \pm 0,21$ e $5,88 \pm 0,15$ com 1,5 horas, $6,08 \pm 0,13$ e 5,78 $\pm 0,10 \mathrm{com} 2,5$ horas, 5,98 $\pm 0,11$ e $5,68 \pm 0,01$ na $6^{a}$ hora e $5,91 \pm 0,11$ e $5,59 \pm 0,08$ com 18,5 horas, respectivamente. As comparações realizadas pelo teste de Tukey revelaram não existir diferença significativa $(\mathrm{p}>0,05)$ entre os valores médios de $\mathrm{pH}$ no músculo Gastrocnemius nos intervalos de tempo de 0,25 horas e 1,5 horas e no músculo Pectoralis nos intervalos 1,5 horas e 2,5 horas após a sangria (Figura 1). Os valores médios de $\mathrm{pH}$ obtidos no presente estudo concordam com os observados por Alvarado e Sams (2000a), que encontraram pH inicial de $6,33 \pm 0,01$ no músculo Pectoralis de perus e por Ma e Addis (1973) que verificaram um $\mathrm{pH}$ médio inicial de 6,20 $\pm 0,2$. Da 
mesma forma, Lesiak et al. (1996) estudaram as alterações post mortem em coxa e peito de perus e obtiveram $\mathrm{pH}$ inicial de 6,44 para a coxa e 6,27 para o peito e $\mathrm{pH}$ final de 5,65 e 5,50 e concluíram que a temperatura de armazenamento e o tempo de estocagem influenciaram significativamente a queda do $\mathrm{pH}$ post mortem. O mesmo não se pode dizer do trabalho de Molette et al. (2003), que estudando as alterações post mortem de 15 perus no músculo Pectoralis major, verificaram que a temperatura de armazenamento não teve efeito sobre as mudanças de $\mathrm{pH}$, mas as médias iniciais (10 min.) de $6,24 \pm 0,03\left(4^{\circ} \mathrm{C}\right) ; 6,25 \pm 0,03\left(20^{\circ} \mathrm{C}\right) ; 6,24 \pm 0,03\left(40^{\circ} \mathrm{C}\right)$ concordam com os trabalhos citados anteriormente.

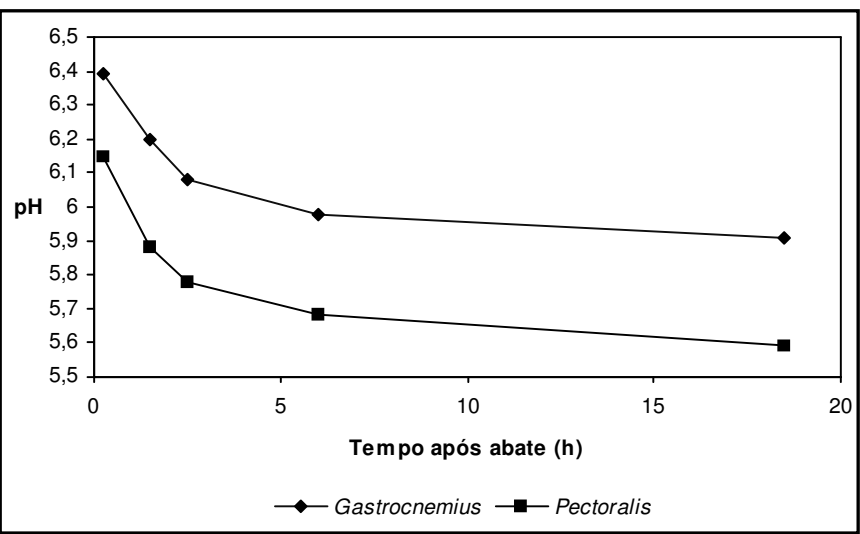

Figura 1: Variação dos valores médios de pH dos músculos Gastrocnemius e Pectoralis de seis carcaças de perus, nos diferentes tempos após abate, durante o resfriamento industrial no Matadouro Frigorífico da Perdigão Agroindustrial S.A., Carambeí, PR, 2004.

Ao estudar as mudanças estruturais nos músculos durante o processo de rigor mortis observou-se contração máxima em ambos músculos com 0,25 horas após a sangria, ou seja, o Gastrocnemius 1,59 $\mu \mathrm{m}$ e o Pectoralis 1,61 $\mu \mathrm{m}$ (Figura 2).

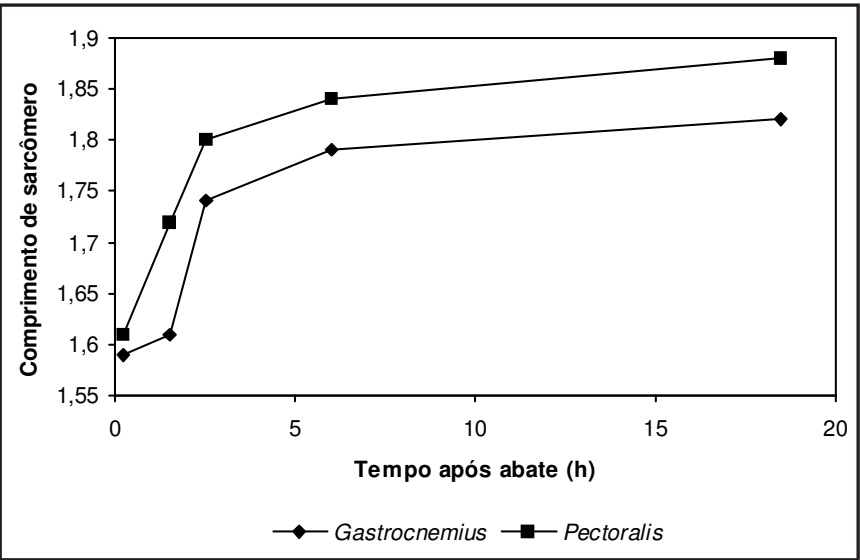

Figura 2: Variação dos valores médios do comprimento de sarcômero dos músculos Gastrocnemius e Pectoralis de seis carcaças de perus, nos diferentes tempos após abate, durante o resfriamento industrial no Matadouro Frigorífico da Perdigão Agroindustrial S.A., Carambeí, PR, 2004

Com 18,5 horas os músculos Gastrocnemius e Pectoralis apresentaram maior comprimento de sarcômero, respectivamente $1,82 \mu \mathrm{m}$ e $1,88 \mu \mathrm{m}$. Na comparação dos valores médios do comprimento de sarcômero no músculo Gastrocnemius não houve diferença significativa nos intervalos de tempo de $0,25 \mathrm{~h}$ e $1,5 \mathrm{~h}, 2,5 \mathrm{~h}$ e $6,0 \mathrm{~h}, 2,5 \mathrm{~h}$ e $18,5 \mathrm{~h}$ e $6,0 \mathrm{~h}$ e 18,5h. Em relação ao músculo Pectoralis não houve diferença significativa $(p>0,05)$ nos intervalos de tempo de 2,5h - 6,0h; $2,5 \mathrm{~h}-18,5 \mathrm{~h}, 6,0 \mathrm{~h}-18,5 \mathrm{~h}$. As fotomicrografias do músculo Pectoralis mostram a variação do tamanho de sarcômero durante o desenvolvimento do processo de rigor mortis de $1,61 \mathrm{~mm}(0,25 \mathrm{~h})$, de $1,80 \mu \mathrm{m}(2,5 \mathrm{~h})$ e de $1,88 \mu \mathrm{m}(18,5 \mathrm{~h})$ após a sangria (Figura 3 ).

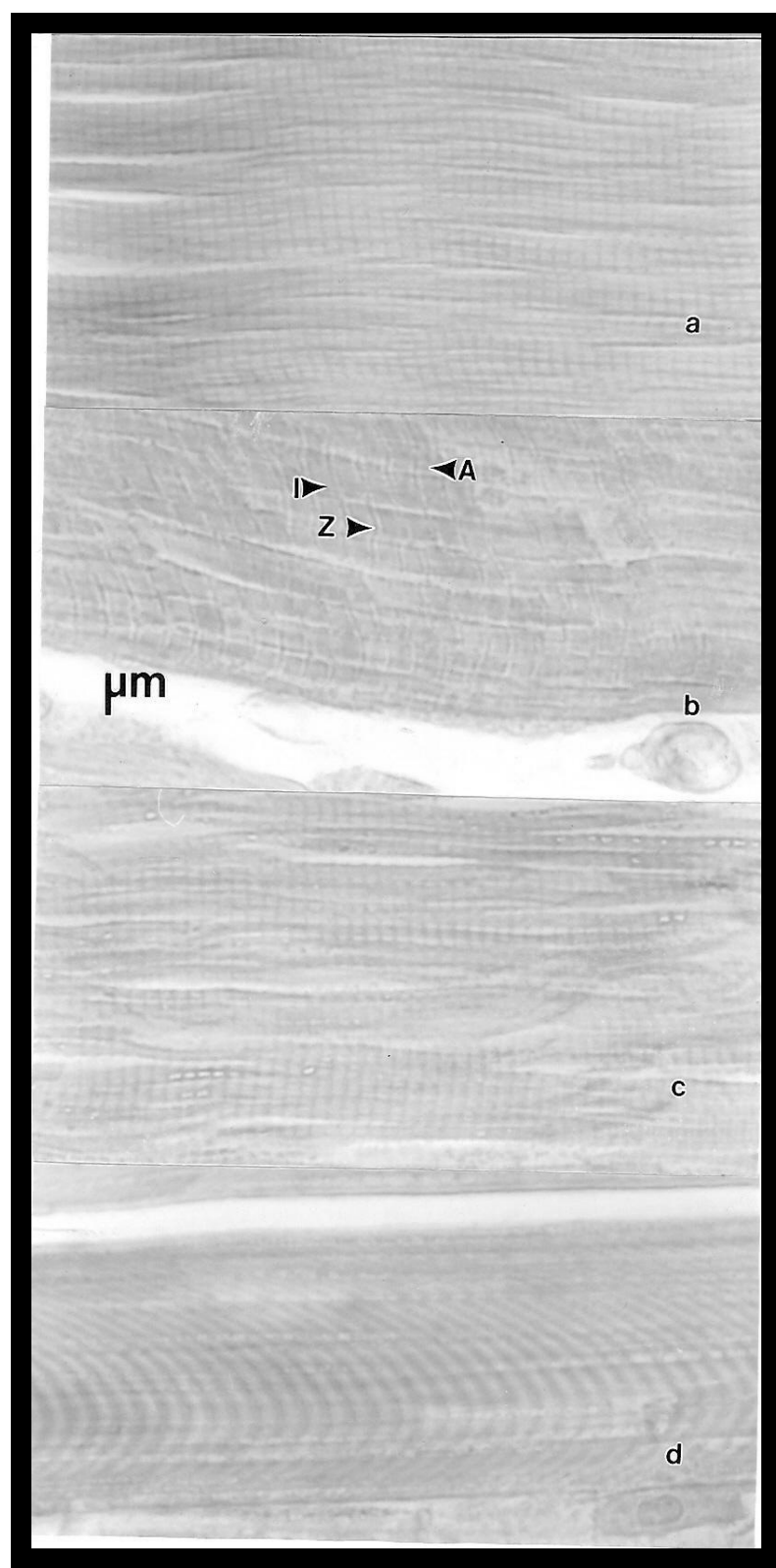

Figura 3: Fotomicrografias ópticas do músculo Gastrocnemius (G) e Pectoralis $(P)$ durante o resfriamento industrial mostrando as bandas A, I e disco Z (aumento de 1000 vezes), fixado com formalina tamponada neutra e corado com hematoxilina fosfotúngsta de Mallory: a) músculo $G$ aos 15 minutos após a sangria e b) com 18,5 horas após a sangria; c) músculo $P$ aos 15 minutos após a sangria e d) com 18,5 horas após a sangria. 
A velocidade das mudanças bioquímicas que ocorrem no post mortem é influenciada pela temperatura e importante nas características sensoriais da carne. Desse modo, foram encontrados em carcaças de perus resfriadas a $0^{\circ} \mathrm{C}$ por 4 horas, tamanho de sarcômero de 1,89 $\mu \mathrm{m}$ no músculo Pectoralis (Mckee e Sams, 1998). O valor encontrado está em concordância com o presente estudo $(1,88 \mu \mathrm{m})$. Em trabalho semelhante (Lesiak et al., 1996) observaram um tamanho de sarcômero de 1,63 $\mu \mathrm{m}$ no músculo Pectoralis de perus a $0^{\circ} \mathrm{C}$ em 4 horas. Esses valores discordam dos encontrados nesta pesquisa, provavelmente em virtude da mensuração ter sido realizada com o músculo desossado e sem o adequado anteparo para evitar o seu encurtamento.

A velocidade das mudanças bioquímicas que ocorrem no post mortem é influenciada pela estimulação elétrica. Desse modo, Owens e Sams (1997) encontraram em carcaças de perus estimulados eletricamente $(570 \mathrm{v}, 450 \mathrm{~mA}, 60 \mathrm{~Hz})$ durante 2 segundos, tamanho de sarcômero de $1,78 \mu \mathrm{m}$ no peito de carcaças estimuladas e 1,66 $\mu \mathrm{m}$ em carcaças não estimuladas 2 horas após o abate. Esses resultados concordam com os valores de 1,72 $\mu \mathrm{m}$ em 1,5 horas e 1,80 $\mu \mathrm{m}$ em 2,5 horas no músculo Gastrocnemius do presente trabalho, em concordância Alvarado e Sams (2000a) descreveram que a aceleração do metabolismo muscular retarda o processo do rigor mortis e ajuda a evitar o encurtamento pelo frio que pode ocorrer durante o resfriamento das carcaças, provavelmente devido à deficiente reserva de energia capaz de promover a contração do músculo.

Os valores médios de força de cisalhamento encontrados para o músculo Gastrocnemius foram de: $9,50 \mathrm{~kg}(0,25 \mathrm{~h}), 8,90 \mathrm{~kg}$ (1,5h), $7,85 \mathrm{~kg}(2,5 \mathrm{~h}), 7,07 \mathrm{~kg}(6,0 \mathrm{~h})$ e $6,23 \mathrm{~kg}(18,5 \mathrm{~h})$ e para o músculo Pectoralis foram de $10,30 \mathrm{~kg}(0,25 \mathrm{~h}), 9,50 \mathrm{~kg}(1,5 \mathrm{~h})$, $7,94 \mathrm{~kg}$ (2,5h), 7,08 kg (6,0h) e 6,45 kg (18,5h). Resultados semelhantes foram relatados por Alvarado e Sams (2000a) que encontraram valores de $7,75 \mathrm{~kg}$ a $13,61 \mathrm{~kg}$ no músculo Pectoralis de perus não estimulados eletricamente e de 7,19 $\mathrm{kg}$ a $16,22 \mathrm{~kg}$ no mesmo músculo de perus estimulados. Valores de $7,31 \mathrm{~kg}$ a $9,69 \mathrm{~kg}$ foram descritos para o músculo Pectoralis (Mckee e Sams, 1998) e valor médio de 8,04 kg em carcaças estimuladas foram descritos para o músculo Pectoralis 2 horas após o abate dos animais (Owens e Sams, 1997), concordando com a força de cisalhamento observada no presente estudo $(7,94 \mathrm{~kg})$. Por outro lado, valores maiores $(12,13 \mathrm{~kg}$ a $13,42 \mathrm{~kg})$ foram encontrados no músculo Pectoralis de frangos não estimulados (Alvarado e Sams, 2000b). Esses resultados maiores de força de cisalhamento podem ser explicados pelo fato que em carcaças não estimuladas o processo do rigor mortis é mais lento, resultando num maior comprimento de sarcômero e menor maciez do músculo (Owens e Sams, 1997). De acordo com Alvarado e Sams (2000a) os dois músculos estudados podem ser considerados como macios, pois apresentaram a força de cisalhamento próximo de $6,0 \mathrm{~kg}$.

Os testes de correlação demonstraram média correlação linear negativa entre temperatura da carcaça e tempo após abate $(r=-0,69)$ e alta correlação negativa entre $\mathrm{pH}$ e tempo após abate para os músculos Gastrocnemius e Pectoralis $(r=$ $-0,78$ e $r=-0,76$, respectivamente). Observou-se, ainda, alta correlação linear positiva entre tempo e comprimento de sarcômero dos músculos Gastrocnemius e Pectoralis $(r=0,77$ e $r=0,76)$; correlação linear negativa alta entre $\mathrm{pH}$ e comprimento de sarcômero dos músculos Gastrocnemius e Pectoralis $(r=-0,96$ e $r=-0,99)$. Observou-se, também, correlação negativa alta entre temperatura das carcaças e comprimento de sarcômero para os músculos Gastrocnemius e Pectoralis $(r=-0,93$ e $r=-1,00)$. Os valores médios obtidos em cada tempo após o abate estão representados em modelos gráficos (Figuras 1 e 2).

A perda de peso por cocção nos diferentes intervalos de tempo caracterizou-se como significativamente menor $(p<0,05)$ na primeira verificação $(0,25$ horas) para ambos os músculos, sendo $25,52 \%$ para Gastrocnemius e 22,33\% para Pectoralis, aumentando até o final do processo de rigor mortis, atingindo $31,61 \%$ e $28,38 \%$, na mesma ordem. Assim como Papinaho e Fletcher (1996) para Pectoralis major de frangos, relataram perda de $25,0 \%$ em 0,2 horas e $31 \%$ em 24 horas post mortem. Em concordância, Alvarado e Sams (2000b) encontraram $20,37 \%$ no início $(0,25 \mathrm{~h})$ e $32,55 \%$ no final do rigor mortis (24 horas) para essa medida de qualidade da carne de frangos, Resultados inferiores foram relatados por Owens e Sams (1997) que determinaram média de perda por cozimento de 18 peitos de perus de $10,87 \%$ sendo correspondente ao período de 2 horas post mortem, $11,04 \%$ nas 8 horas e 13,91\% em 24 horas post mortem, provavelmente devido a maior capacidade de retenção de água da carne dessas aves.

\section{Conclusões}

As quedas da temperatura e do $\mathrm{pH}$ das carcaças de perus durante o resfriamento industrial acompanharam 0 desenvolvimento normal do processo de rigor mortis;

A contração máxima durante o processo de rigor mortis, caracterizada pelo menor comprimento de sarcômero e maior força de cisalhamento, se estabeleceu 15 minutos após sangria nos dois músculos estudados;

A maciez desses músculos foi inversamente proporcional ao comprimento de seus sarcômeros, acompanhando o processo normal de resolução do rigor mortis, sendo maior no músculo Pectoralis (carne dura) e menor no músculo Gastrocnemius (carne macia).

\section{Agradecimentos}

Ao CNPq e à Perdigão Agroindustrial S.A., Carambeí, PR.

\section{Referências}

ALVARADO, C. Z.; SAMS, A. R. Rigor mortis development in turkey breast muscle and the effect of electrical stunning. Poultry Science, v. 79 , p. 1694-1698, 2000a.

ALVARADO, C.Z.; SAMS, A.R. The influence of postmortem electrical stimulation on rigor mortis development, calpastatin activity, and tenderness in broiler and duck. Poultry Science, v. 79, p. 1364-1368, $2000 \mathrm{~b}$. 
ANTUNES, R. Abrindo caminhos. Revista Avicultura Industrial. v. 91 , n. 1, 2003.

BEHMER, O. A.; JORDENS, J.Z.; GRIFFITS, D. T.; BENEZ, S. M. Manual de técnicas para histologia normal e patológica. São Paulo: EDART Editora da USP, 1976, $239 p$.

BERNARD, D.M.; ROBERT, J.H.; JOSEPH, G. S.; CUVELIER, M.-E. Effect of antemortem electrical stunning on functional properties of turkey muscle. Poultry Science. v. 67, p. 1062-1068, 1988.

BRASIL. Ministério da Agricultura e do Abastecimento. Secretaria de Defesa Agropecuária. Regulamento Técnico da Inspeção Tecnológica e Higiênico-Sanitária de Carne de Aves. Portaria n² 210, de 10 de Novembro de 1998.

KERTH, C.R.; JOHNSON, L.A.; LUCAS, E. W.; JONES, W.R. Improvement of beef tenderness and quality traits with calcium chloride injection in beef loins 48 hours post mortem. Journal of Food Science, v. 73, p. 750-756, 1995.

KHAN, A.W. Effect of temperature during post-mortem glycolysis and dephosphorylation of high energy phosphates on poultry meat tenderness. Journal of Food Science, v. 36, p. 120-121, 1971.

LANDES, D.R.; DAWSON, L.E.;PRICE, J.F.; SHACCKELFORD, L. A. Protein extractability of turkey breast muscle exhibiting different rates of postmortem glyclosis. Journal of Food Science. v. 36, p. 122-124, 1971.

LESIAK, M.T.; OLSON, D.G.; LESIAK, C.A.; AHN, D.U.; KROPF, D.H Effects of post mortem temperature and time on the water-holding capacity of hot-boned turkey breast and thigh muscle. Meat Science, v. 43, p. $51-60,1996$.
LYON, B.G.; LYON, C.E. Sensory descriptive profile relationship to shear values of deboned poultry. Journal of Food Science. v. 62, p. 885-888, 1997.

MA, R.T.I.;ADDIS, P.B. The association of struggle during exsanguinations to glycolysis, protein solubility and shear in turkey pectoralis muscle. Journal of Food Science, v. 38, p. 995-997, 1973.

MCKEE, S.R.; SAMS, A.R. Rigor mortis development at elevated temperature induces pale exudative turkey meat characteristics. Poultry Science, v. 77, p. 169-174, 1998.

MOLETTE, C.; RÉMIGNON, R.; CUNNINGHAM, F.E.; BUCKLEY, D.J. Maintaining muscles at a high post-mortem temperature induces PSElike meat in turkey. Meat Science, v. 63, p. 525-532, 2003.

OWENS, C.M.; SAMS, A.R. Muscle metabolism and meat quality of Pectoralis from turkeys treated with postmortem electrical stimulation. Poultry Science. v. 76, p. 1047-1051, 1997.

PAPINAHO, P.A.; FLETCHER, D.L. The effects of stunning amperage and deboning time on early rigor development and breast meat quality of broilers. Poultry Science. v. 75, p. 672-676, 1996.

SAS Institute. SAS ${ }^{R}$ User's guide: SAS Institute INC. Cary, 1985, 959p. SHIMOKOMAKI, M.; ELSDEN, D.F.; BAILEY, A.J.; HEATH, J.L. Meat tenderness: age related changes in bovine intra muscular collagen. Journal of Food Science. v. 37, p. 892-896, 1972.

SLOSS, M.W.B.S.; KEMP, R.L.A.B. Veterinary clinical parasitology. 5. ed. lowa: lowa State University Press. 1978, 247 p. 